\title{
Long-Term Results of Open Heart Repair of Ventricular Septal Defect
}

\author{
Yuzuru Kagawa, Togo Horiuchi, Takashi Ito, \\ Yasuyuki Suzuki, Kiyoshi Haneda, Eiji Ishizawa, \\ Satoru Arai, Yoshinito Sekino and Naoshi Sato \\ The Department of Thoracic and Cardiovascular Surgery, \\ Tohoku University School of Medicine, Sendai 980
}

\begin{abstract}
Kagawa, Y., Horiuchi, T., Ito, T., Suzuki, Y., Haneda, K., Ishizawa, E., Arai, S., Sekino, Y. and Sato, N. Long-Term Results of Open Heart Repair of Ventricular Septal Defect. Tohoku J. exp. Med., 1987, 151 (1), 1-14_Longterm follow-up results of 321 patients who underwent open hert repair of ventricular septal defect in our institute and have lived for more than five years were analyzed using questionnaires. The follow-up period was up to 24 years with an averagr of 12.9 years. The questionnaire mainly concerned the patient's state of health. Beside this, IQ was measured in 52 children, ECG was analyzed in 92 patients and heart catheterization was performed on 21 patients with preoperative severe pulmonary hypertension $(\mathrm{PH})$. From this survey, it was ascertained that (1) no desths resulted from cardiac disorders ; (2) physical activity and development were satisfactory in nearly all patients ; $(3)$ the scholastic acheivement score was within the normal range in nearly all school children; (4) among 30 live births from 24 adult female patients, two babies with simple cardiac anomalies were found and (5) there remained very few patients suffering from residual $\mathrm{PH}$, residual shunt or conduction disturbances. IQ as tested by individual intelligence tests was within the normal range in all children. On ECG, complete right bundle branch block with left anterior hemiblock was found in $9 \%$ and complete atrioventricular block in 7\%. Amelioration of $\mathrm{PH}$ was achived especially in those who underwent operations in their younger years. ventricular septal defect; open heart repair ; long-term results ; quality of life ; pulmonary hypertension
\end{abstract}

Ventricular septal defect (VSD) is the most common congenital cardiac anomaly and is found in about $30 \%$ of infants and children with congenital heart disease (Brinsfield and Plauth 1978). Patients with isolated small VSD are usually asymptomatic except for a typical systolic murmur. In addition, VSD has a tendency to close or become narrower spontaneously during infancy or in early childhood (Keith et al. 1971 ; Collins et al. 1972 ; Blackstone et al. 1976).

Received August 18, 1986; accepted for publication November 7, 1986.

Adress all correspondence: Yuzuru Kagawa, M.D. Department of Thoracic and Cardiovascular Surgery, Tohoku University School of Medicine, 1-1 Seiryo-machi, Sendai, Japan. 
But it is characteristic for the patients with large VSD to present poor weight gain, frequent respiratory infection, congestive heart failure and even death in early stage of life. It was reported that approximately $9 \%$ of patients with large VSD die within the first year of life without surgical repair (Keith et al. 1971). Moreover the tendency to develop pulmonary vascular obstructive disease, which can become irreversible, is high (Blackstone et al. 1976; Rizzoli et al. 1980). Surgical closure of VSD was first attempted in 1954, by means of controlled cross-circulation using a human adult as a heart lung machine (Lillehei et al. 1955). Intracardiac repair of large VSD using a mechanical pump-oxygenator was reported in 1955 (Kirklin et al. 1955) and Horiuchi reported radical correction of VSD in infancy by means of hypothermia and total circulatory arrest in 1963 (Horiuchi et al. 1963). Since the beginning of the era of surgical repair of VSD, many improvements have been made in the field of cardiac surgery and the results of surgical treatment, most of which are performed during infancy have improved remarkably in recent years (Ishizawa et al. 1980 ; Rizzoli et al. 1980 ; Kirklin and Barratt-Boyes 1986). Satisfactory follow-up results were also reported for open heart repair of VSD (Ishizawa et al. 1980; Ito 1980a, b ; Kagawa et al. 1986 ; Kirklin and Barratt-Boyes 1986). Some few problems, however remain such as a residue of pulmonary hypertension $(\mathrm{PH})$, residual VSD or conduction disturbance, which have some influence on the later results of these patients.

The purpose of this paper is to analyze long-term results in patients who underwent open heart repair of VSD in our institute and have lived for more than five years after the operation, with special refence to the evaluation of their quality of life and analysis of postoperative problems.

\section{Subjects and Methods}

Of the 702 patients who have undergone open heart repair of VSD in our institute since 1960, 625 patients have survived the operation and lived for more than five years postoperatively. To evaluate the long-term postoperative state of health, questionnaires were sen to these 625 patients. Questionnaires concerned mainly physical and mental developments, scholastic achievements and participation in physical education and extracurricular activity in school children and high school students, and state of health, postoperative physical problems, state of employment and pregnancy and delivery in the female in adult patients. There were 321 replies to the questionnaires received, which constituted the scope of this tudy. The subjects comprised 178 males and 143 females and the age structure at the time of operation was under one year in $25 \%$, between one and three in $15 \%$ and over 10 years in the ramaining $60 \%$. There were 53 patients with other associated cardiac anomalies, which consisted of patent ductus arteriosus in 21, pulmonary stenosis in 15, atrial septal defect in 12 and coarctation of the aorta in five patients. Associated cardiac anomalies were repaired simultaneously or prior to open heart repair of VSD. Associated congenital valvular lesion was found in 15 patients, comprising aortic regurgitation (AR) in 10 and mitral regurgitation (MR) in five patients. Surgical interventions were not performed, as regurgitation was trivial in all patients. There were 125 patients associated with $\mathrm{PH}$, whose ratio between pulmonary and systemic pressure $(\mathrm{Pp} / \mathrm{Ps})$ exceeded 0.4 preoperatively. Nine patients, consisting of eight females and one male had Down's syndrome. With regard to physical development prior to operation, body weight was under the 3rd percentile of 
TABLE 1. Characteristics of the subjects

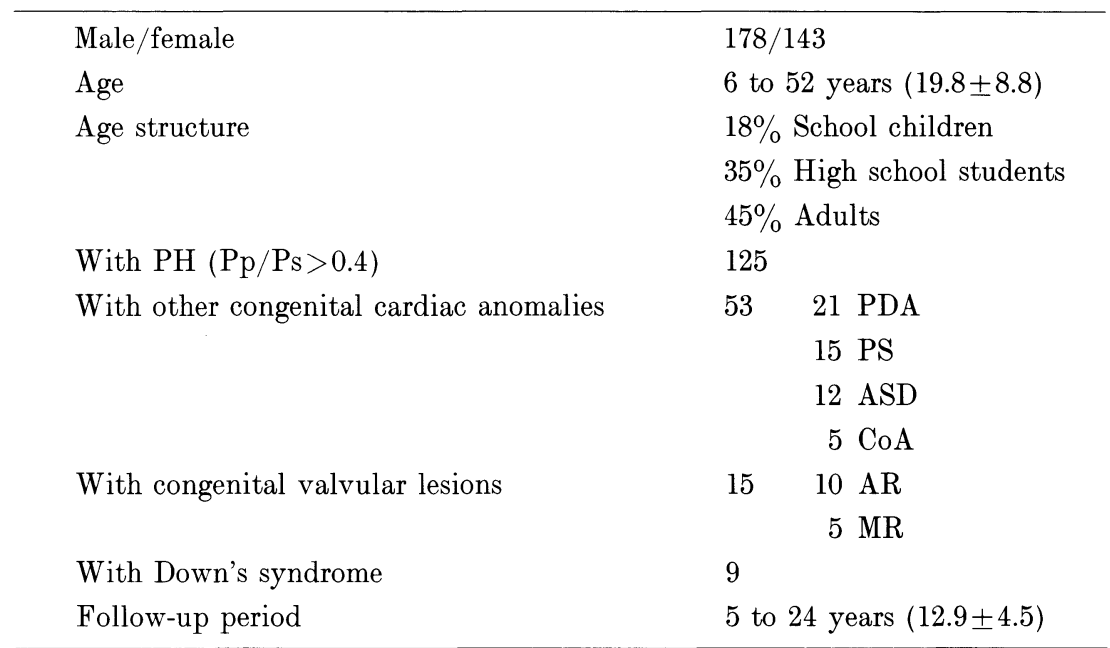

$\mathrm{PH}$, pulmonary hypertension; $\mathrm{Pp} / \mathrm{Ps}$, ratio between pulmonary and systemic pressure; PDA, patent ductus arteriosus; PS, pulmonary stenosis; ASD, atrial septal defect; CoA, coarctation of the aorta; MR, mitral regurgitation; AR, aortic regurgitation; ( ), mean \pm s.D.

normal in $52 \%$ of the patients under three years. The age at the time of this survey ranged from six to 52 years, with an average of $19.8 \pm 8.8$ years and age structure was $18 \%$ school children (under 12 years), 35\% high school students (between 12 and 18) and $47 \%$ college students or full-fledged members of society (over 18 years). Follow-up period ranged from five to 24 years with an average of $12.9 \pm 4.5$ years (Table 1 ).

In addition to the questionnarie, intelligence quotient (IQ) was measured in school children and junior high school students. Group intelligence tests were performed for 52 and individual intelligence tests for 32 patients. Scholastic achievement score was evaluated according to the 5 degree evaluation scale, commonly used in Japanese schools, with 5 representing the upper and 1 the lower limits and the mean value of several subjects was used.

Heart catheterization was carried out for those with associated severe $\mathrm{PH}(\mathrm{Pp} / \mathrm{Ps}>$ $0.75)$, MR or AR preoperatively.

ECG was examined in 94 patients, who attended the out-patient clinic.

\section{RESULTS}

\section{Late mortality and functional class}

There were three late deaths in this survey (Table 2). Physical activity for all patients, according to the New York Heart Association (NYHA) classification was grade I in $97 \%$ and grade II in the remaining $3 \%$. There were 15 patients who complained of symptoms giveng the impression of cardiac disorder, such as palpitation, easy fatiguability or arrhythmia. Subjective improvements in physical condition was acieved in $97 \%$. The remaining $3 \%$ of the patients felt that there were no or very few improvements (Fig. 1A). In 170 school children and high school students, Physical activity was grade I in $97.7 \%$ and grade II in the 
TABLE 2. Late deaths

\begin{tabular}{ccclc}
\hline Case & $\begin{array}{c}\text { Sex and age } \\
\text { at operation }\end{array}$ & \multicolumn{1}{c}{ Diagnosis } & \multicolumn{1}{c}{ Cause of death } & $\begin{array}{c}\text { Years after } \\
\text { operation }\end{array}$ \\
\hline 1 & F $\quad 11 \mathrm{mo}$ & VSD, PH & Traffic accident & 7 \\
$2^{*}$ & M $\quad 3$ y & VSD, PDA, PH & Pneumonia & 5 \\
$3 \dagger$ & M $\quad 9$ y & $\begin{array}{c}\text { VSD, Von } \\
\text { Willbrand disease }\end{array}$ & Liver dysfunction, DIC & 5 \\
\hline
\end{tabular}

F, female; M, male; mo, months; y, years ; * left empyema after division of $\mathrm{PDA} ; \dagger$ splenectomy after open heart repair of VSD; DIC, disseminated intravascular coagulation.

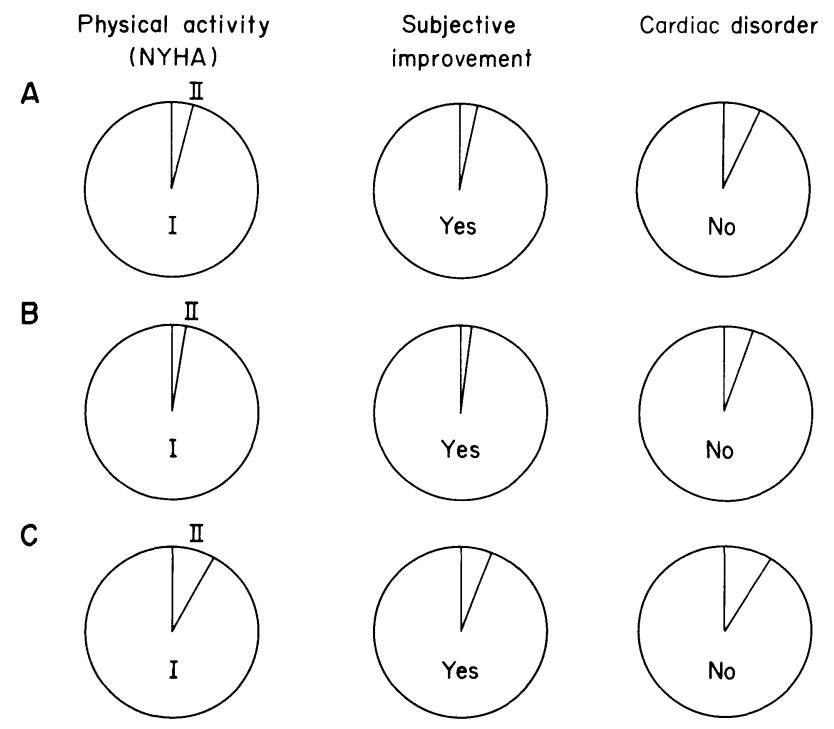

Fig. 1. Living condition of the patients.

$\mathrm{A}$, all patients $(n=321) ; \mathrm{B}$, school children and high school students $(n=$ $170)$; C, adults $(n=151)$.

remaining $2.3 \%$ according to the NYHA classification (Fig. $1 \mathrm{~B}$ ). There were no patients who could not attend school because physical condition. The seven patients with Down's syndrome all attended a school for physically handicapped or mentally retarded children, but physical activities were grade I in all except for one with residual VSD and residue of PH. Ninety-three percent of these young patients enjoyed physical education and sports without any restriction. But remaining $7 \%$ refrained from extremely hard exercise, two thirds because of physical condition and one third because of restrictions set by teachers. As to physical development, the body weight and height of the school children were within normal range except for one child whose height was below the $3 \mathrm{rd}$ percentile of normal development (Fig. 2). In 151 adults, physical activity was grade I in $95 \%$ and grade II in $5 \%$ (Fig. 1C). As to physical development, the 

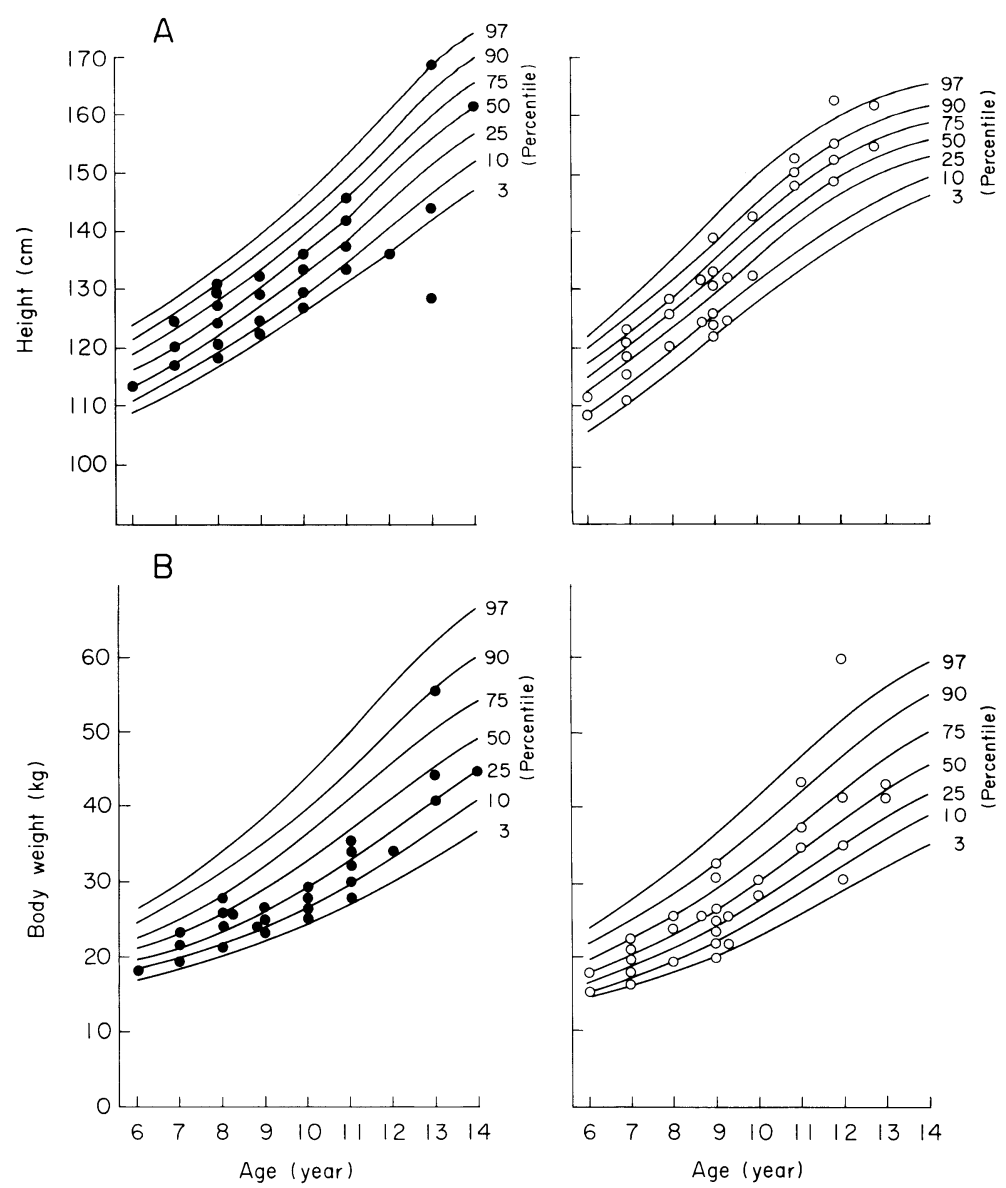

Fig. 2. Body weight and height of the school children and junior high school students.

$\bullet$, male ; $\circ$, female.

mean value of body weight was $60.7 \pm 9.0 \mathrm{~kg}$ in males and $51.9 \pm 5.7 \mathrm{~kg}$ in females (Fig. $3 \mathrm{~A}$ ) and of height $167.0 \pm 6.7 \mathrm{~cm}$ in males and $156.9 \pm 5.7 \mathrm{~cm}$ in females (Fig. 3B). Among 90 males, 11 patients were attending college, and one patient with Down's syndrome was accomodated in a home for physically handicapped or mentally retarded persons. The remaining 78 patients were all employed and leading active social lives. Specification of the work was: heavy labor in 14\%, moderate labor in $63 \%$ and light labor in $23 \%$. Among 61 females, there was one patient with Down's syndrome, who was accomodated in a home for physically handicapped or mentally retarded persons. Thirty-seven were housewives, 19 were employed and three patients were attending college. Specification of work of the 19 patients in employment was as follows : Moderate labor in $68 \%$ and light labor in $32 \%$. The mean age of the adult female group was $27.0 \pm 6.5$ years and there were 24 patients who had given birth to children. Of 33 births, there were 
Y. Kagawa et al.
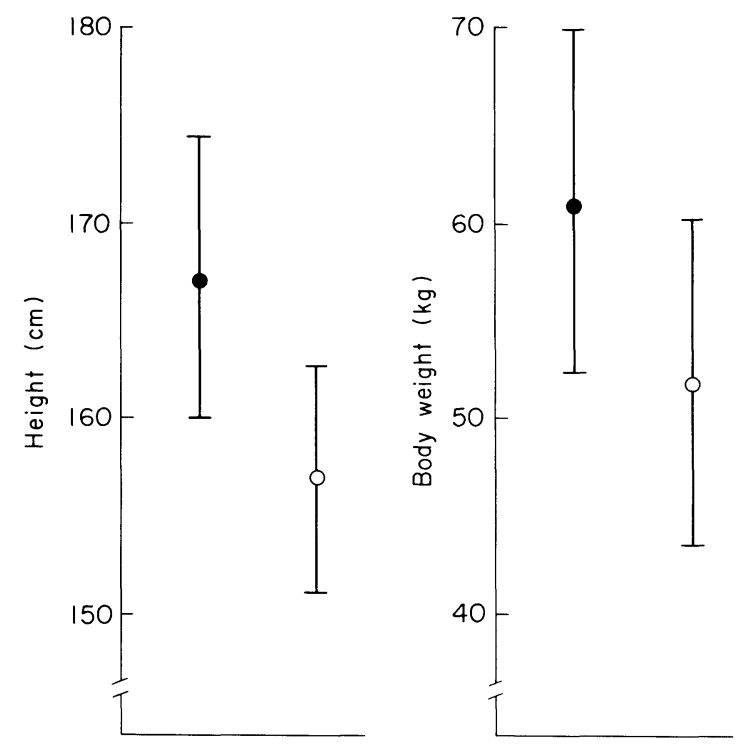

Fig. 3. Body weight and height of the adults.

$\bullet$, male $(n=58) ; 0$, female $(n=47)$

Values are mean \pm s.D.

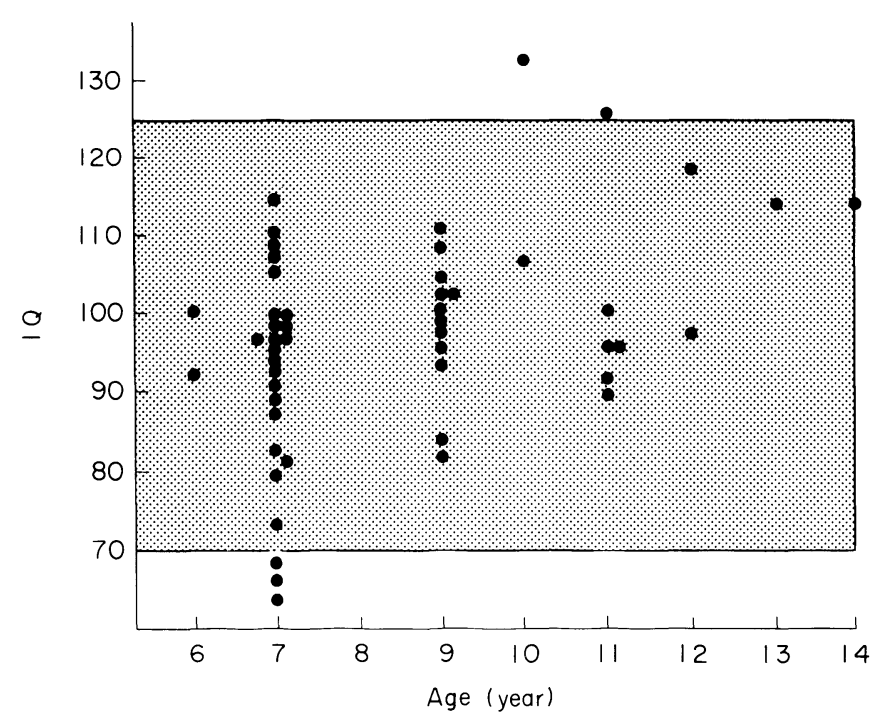

Fig. 4. IQ tested by group intelligence tests. Shaded area represents normal range.

30 live births and no abnormalities were found in 28 babies, but there were two babies with simple cardiac anomaly, one with small VSD and the other with atrial septal defect. 
State of intelligence

IQ evaluated by group intelligence test in 52 patients was between 60 and 134, with an average of 96.0. There were three children, whose score was below 70 (Fig. 4). IQ evaluated by individual intelligence test in 32 patients, including the three children refered to above, was between 88 and 141, with an average of

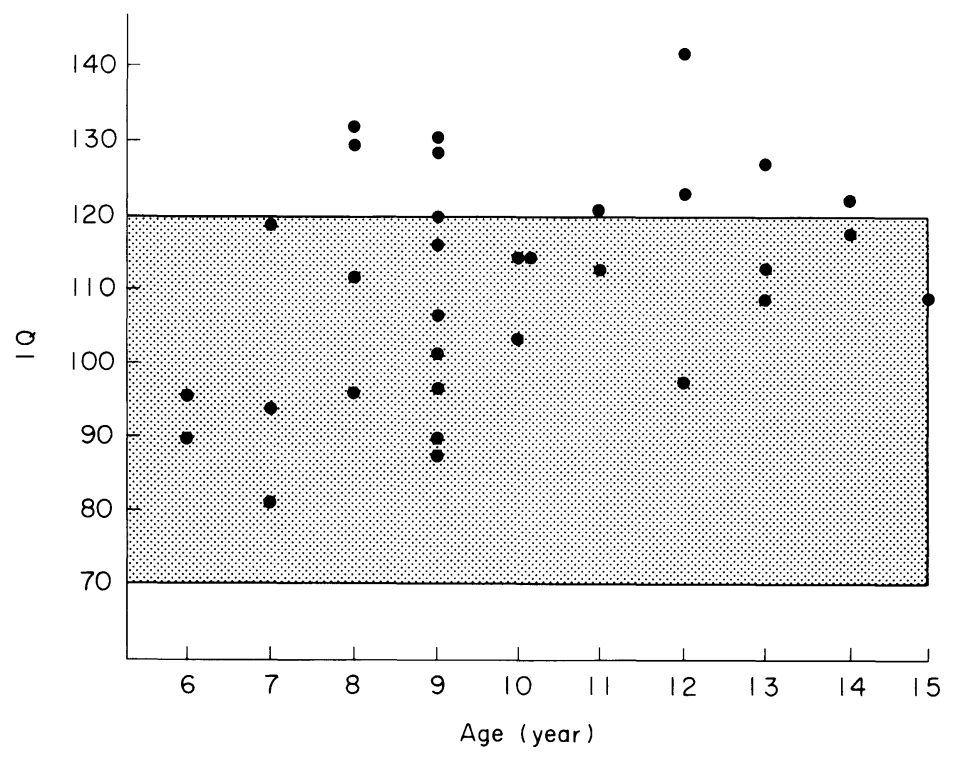

Fig. 5. IQ tested by individual intelligence tests. Shaded area represents normal range.

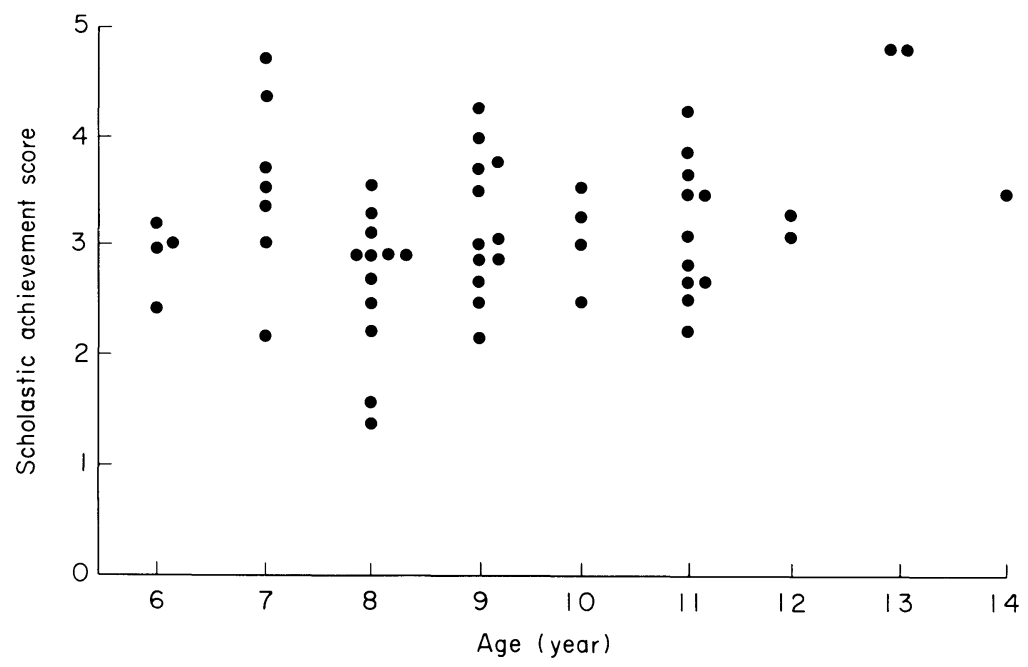

Fig. 6. Scholastic achievement score. 

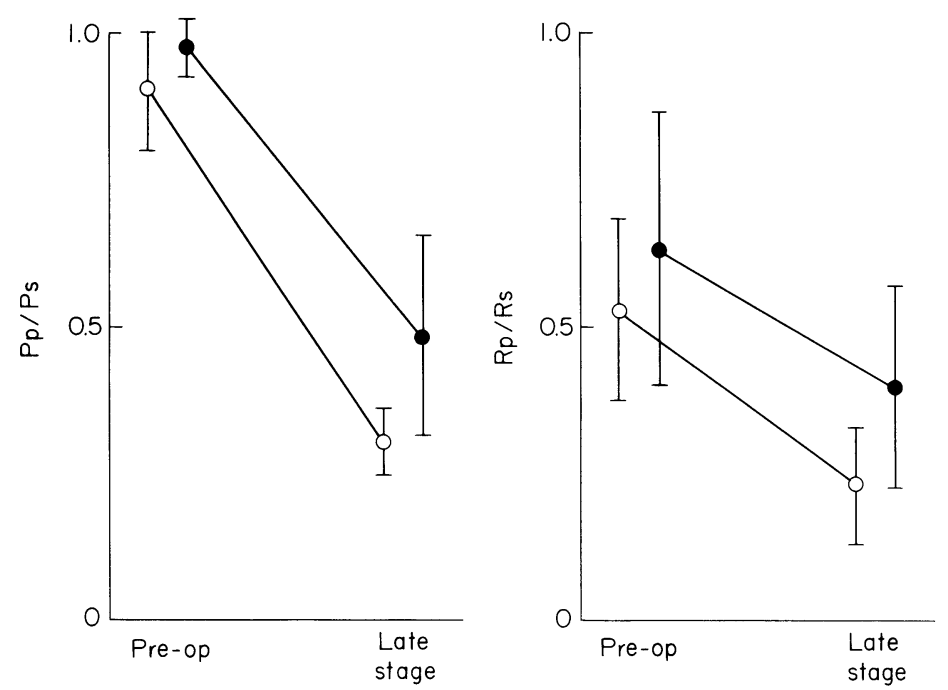

Fig. 7. $\mathrm{Pp} / \mathrm{Ps}$ and $\mathrm{Rp} / \mathrm{Rs}$ before operation and in the late postoperative stage.

-, patients over 5 years of age at the time of operation $(n=7)$; $\odot$, patients under 5 years of age at the time of operation $(n=14)$.

Values are mean \pm s.D.

112. There were no patients whose IQ as evaluated by the individual test was below normal range (Fig. 5). The mean score of scholastic achievement in the 5 degree scale evaluation of 51 school children and five junior high school students was 3. 0. There were two children, whose mean score was 2.0 (Fig. 6).

\section{Hemodynamic evaluation}

Heart catheterization data of 21 patients, whose $\mathrm{Pp} / \mathrm{Ps}$ had been higher than

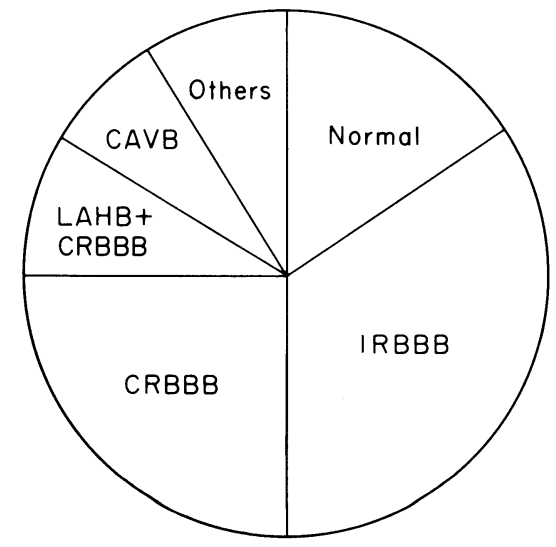

Fig. 8. ECG findings.

IRBBB, incomplete right bundle branch block; $\mathrm{CRBBB}$, complete right bundle branch block; LAHB, left anterior hemiblock; CAVB, complete atrioventricular block. 
0.75 preoperatively revealed improvement in $\mathrm{PH}$. Mean values of $\mathrm{Pp} / \mathrm{Ps}$ before operation and at a late stage were 0.98 and 0.49 in seven patients whose age at operation was over five years and those in 14 patients whose age at operation was under five years were 0.90 and 0.30 respectively. Mean value of rations between pulmonary and systemic vascular resistance $(\mathrm{Rp} / \mathrm{Rs})$ before operation and at a late stage were 0.63 and 0.41 in seeven whose age at operation was over five years and 0.53 and 0.23 in 14 patients whose age at operation was under five years (Fig. 7). There was a residue of $\mathrm{PH}$ in three patients, one with large residual left to right shunt and the other two without residual VSD. These two patients underwent open heart repair of VSD as adults. Residual VSD was found in 14 patients, 10 with trivial shunt and four with large shunt. Four patients with large residual VSD were all symptomatic and re-operation for closure of residual VSD was carried out in three patients. Ten patients with trivial shunt were all asymptomatic except for cardiac murmur. In 10 patients with associated AR, there was no evident aggravation of $\mathrm{AR}$ and in five patients with MR there was one patient who showed a slight aggravation of MR.

\section{Cardiac rhythm}

EGC findings in 94 patients were: normal in 15\%, incomplate right bundle branch block in $35 \%$ and complate right bundle branch block (CRBBB) in $25 \%$. $\mathrm{CRBBB}$ with left anterior hemiblock (LAHB) was found in $9 \%$ and complete atrioventricular block (CAVB) in 7\% (Fig. 8). Pacemaker implantation was carried out in six patients with CAVB. In the one remaining patient, ECG changed from CRBBB with LAHB to CAVB 16 years after operation.

\section{Discussion}

Open heart repair of VSD was first performed in May 1960 in our institute (Horiuchi et al. 1963). In the 26 years that have elapsed since then, indications for VSD surgery have been found in increasingly younger patients. The proportions of patients under one year of age were $21 \%$ in the 122 patients operated upon during the first four years (May 1960 to February 1964) (Horiuchi et al. 1964), and $62 \%$ in the 69 patients in the most recent four years (July 1982 to July 1986) in our institute. Open heart repair of VSD is now mainly indicated for the infants with severe symptoms. Regardless of the increase in the severity of the cases a decrease in the hospital mortality rate has become evident with time (Suzuki et al. 1976 ; Rein et al. 1977; Ishizawa et al. 1980). There have been several reports that hospital mortality for open heart repair of isolated VSD has reached zero percent (Rizzoli et al. 1980 ; Kirklin and Barratt-Boyes 1986). In our institute, there was no deaths among the patients who underwent open heart repair of VSD during the most recent four years, including those with other associated cardiac anomalies. In the current era, risks of hospital mortality with open heart repair of VSD are very low in centers with sufficient experience and equipment for this 
type of surgery.

There have been several reports regarding satisfactory late postoperative results for open heart repair of VSD (Rein et al. 1977; Rizzoli et al. 1980 ; Kirklin and Barratt-Boyes 1986). We also have reported that intermediate and long-term postoperative results were satisfactory and that nearly all patients were leading normal or near normal lives (Ishizawa et al. 1980 ; Ito $1980 \mathrm{a}, \mathrm{b}$; Kagawa et al. 1986). In this survey, which draws upon nearly half of the total number of patients surgically treated, a high quality of life was also ascertained, and this results seems to express the most recent rasults of open heart repair of VSD tolerably well. Our results concerning late mortality agreed with those of Kirklin and Barratt-Boyes, who stated that deaths resulting from cardiac disorder in the early stage of postoperative periods occur very rarely and that the cause of death is presumed to be arrhythmias, such as ventricular fibrillation or the sudden onset of heart block (Kirklin and Barratt-Boyes 1986). There were no early deaths in this study and causes of three late deaths were not attributable to cardiac disorders.

Physical activity and subjective improvement were satisfactory in nearly all patients and slightly better in younger patients than the adults. Among $7 \%$ of school children and high school students who were refraining from extremely hard exercise, physical exercise was restricted by teachers without regard to the physical ability in one third of these patients only because they were postcardiotomy patients. The final goal of the operation is to let the patient enjoy an active school or social life as long as there are no physical problems. For this purpose, it would be necessary to call public attention to the fact that nearly all patients who have undergone open heart repair of VSD are on an equal basis with respect to physical activity with other persons with no cardiac lesions.

Children with large VSD tend to be small in weight and height prior to operation. In this series, $52 \%$ of the patients under three years of age at the time of operation were under the 3rd percentile of normal physical development of Japanese infants and babies reported by Takaishi (Takaishi et al. 1976) Improved physical development following the repair of VSD has been widely reported (Cartmill et al. 1966 ; Clarkson 1973 ; Messmer et al. 1976 ; Ishizawa et al. 1980 ; Ito 1980 b ; Kagawa et al. 1986). In this series, physical developments were normal in nearly all school children and high shool students, when evaluated according to the development percentile of children and school children (Takaishi et al. 1977). The weight and height of the adults were also within the normal range of Japenese adults according to the report on a survey of national nutrition by the Japanes Ministry of Health and Welfare (Kurita 1972).

As to the intellectual developments, there were several reports that IQ as tested by individual intelligence test was within the normal range in the early stage (Ito et al. 1976) and in the late postoperative stage (Stevenson et al. 1974; Messmer et al. 1976 ; Ito $1980 \mathrm{a}, \mathrm{b})$. In this series, there were three patients whose 
IQ was below normal when tested by group intelligence tests. IQ tested by group intelligence test tends to be lower than that tested by individual tests, as the results can be influenced by the age and the time limit for the test. But the IQ of these three patients was within the normal range when tested by individual tests. There were two patients whose scholastic achievement score was below 2.0. It was difficult to decide whether these results were sequelae of the operation, as these patients were all in the lower grades of elementary school and had no abnormal findings in neurological and electroencephalographic examinations.

There were several reports regarding the familial occurence of congenital heart disease, that is, the incidence of the birth of a babies with congenital heart disease from a parent with such a disease is higher than normal (Nora and Nora 1978 ; Friedman 1980). Among the 30 live births, there were two babies associated with simple congenital cardiac anomalies in this survey. But it was quite difficult to decide whether this fact arose from hereditary transmission or not, as the details of the course of pregnancy such as maternal viral illness were not confirmed in these two patients.

In the patients associated with severe $\mathrm{PH}$ preoperatively, $\mathrm{Pp} / \mathrm{Ps}$ and $\mathrm{Rp} / \mathrm{Rs}$ decreased in the late postoperative period. But improvement was much smaller in patients operated upon at a more advanced age. A residue of $\mathrm{PH}$, if present after operation, may become worse with the passage of time and cause premature death after recovery (DuShane and Kirklin 1973; Friedli et al. 1974 ; Blackstone et al. 1976). But some patients with a residue of $\mathrm{PH}$ can live longer, although there is a decline in exercise tolerance with time (DuShane and Kirklin 1973). The results are better when the patients are operated on at a less advenced age (Lillehei et al. 1968 ; Barratt-Boyes et al. 1976 ; Sigmann et al. 1977 ; Ishizawa et al. 1980). There were three patients with a residue of $\mathrm{PH}$, one resulting from residual VSD and the other two from obstructive pulmonary vascular disease. It was caharacteristic that in the latter two patients operations were performed in their adulthood. From this fact, it is evident that early repair of VSD is important in patients with $\mathrm{PH}$ preoperatively. There were four patients with postoperative left to right shunt, large enough to require re-operation. To avoid this complication, more precise surgical techniques are required. In those with small shunt, though they are aymptomatic except for the typical heart murmur of VSD, the possibilities of endocarditis should always be considered in follow-up.

Conduction disturbances after repair of VSD are not rare. Of these, CRBBB with LAHB and CAVB are of importance. The incidence of CRBBB with LAHB after repair of VSD was reported as being between 8 to $17 \%$ according to previous reports (Barratt-Boyes et al. 1976 ; Lincoln et al. 1977 ; Rein et al. 1977). The combination of CRBBB and LAHB tends to bring out a significant increase in CAVB and can cause sudden death in the late postoperative period (Wolff et al. 1972). Although there was controversial report regarding the outcome of CRBBB with LAHB (Steeg et al. 1975), it would be important to follow the ECG 
of such patients very carefully, as there was one patient who showed CAVB at a late stage in this series. The incidence of CAVB, which is the most serious conduction disturbance, was reported as nearly $10 \%$ in previous reports (Fryda et al. 1971; Haneda et al. 1975). In this series, there were seven patients with CAVB, and pacemaker implantation was performed in six patients. Pacemaker implantation is the most effective treatment for the prevention of sudden death and symptoms associated with CAVB. But as there still remain problems resulting from pacemaker complication (Kagawa et al. 1974) the quality of life of these patients is impaired. Recently, the incidence of CAVB after closure of VSD has been decreasing remarkably, consequent upon developments in the understanding of surgical anatomy and electrophysiology of the conduction system (Kirklin and Barratt-Boyes 1986). In our institute, there was no persistent CAVB in 69 patients who underwent open heart repair of VSD during the most recent four years.

Late follow-up results of the patients who had undergone open heart repair of VSD were satisfactory. But it should be emphasized that there still remain a few patients who suffer from residue of $\mathrm{PH}$, residual VSD and conduction disturbance. It is of importance, to obtain better results, to choose an appropriate time for the operetion, to perform the operation as meticulously as possible and to provide sustained and detailed care in follow-up.

\section{References}

1) Barratt-Boyes, B.G., Neutze, J.M., Clarkson, P.M., Shardy, G.C. \& Brandt, P.W.T. (1976) Repair of ventricular septal defect in the first two years of life using profound hypothermia-circulatory arrest technique. Ann. Surg., 184, 376-390.

2) Blackstone, E.H., Kirklin, J.W., Bradley, E.L., DuShane, J.W. \& Appelbaum, A. (1976) Optimum age and results in repair of large ventricular septal defect. $J$. thorac. cardiovasc. Surg., 72, 661-679.

3) Brinsfield, D.E. \& Plauth, W.H. (1978) Clinical recognition and medical management of congenital heart dissease. In : The Heart, Arteries and Veins. 4th ed., edited by L.W. Hurst, R.B. Longue, R.C. Schlant \& N.S. Wenger, A Blackiston Publication, New York, pp. 831-901.

4) Cartmill, T.B., DuShane, J.W., McGoon, D.C. \& Kirklin, J.W. (1966) Results of repair of ventricular septal defect. $J$. thorac. cardiovasc. Surg., 52, 487-501.

5) Clarkson, P.M. (1973) Growth following corrective cardiac operation in early infancy. In: Heart Disease in Infancy: Diagnosis and Surgical Treatment, edited by B.G. Barratt-Boyes, Churchill Livingstone, London, p. 75 .

6) Collins, G., Calder L., Rose, V., Kidd, L. \& Keith, J. (1972) Ventricular septal defect: Clinical and hemodynamic changes in first five years of life. Amer. Heart. $J$., 84, 695-705.

7) DuShane, J.W. \& Kirklin, J.W. (1973) Late results of the repair of ventricular septal defect in pulmonary vascular disease. In: Advance in Cardiac Surgery, edited by J. W. Kirklin, Grune \& Stratton, New York, p. 9.

8) Friedli, B., Kidd, B.S.L., Mustard, W.T. \& Keith, J.D. (1974) Ventricular septal defcet with incresed pulmonary vascular resistance: Late results of surgical closure. Amer. J. Cardiol., 33, 403-409.

9) Friedman, W.F. (1980) Congenital heart disease in infancy and childood. In: 
Heart Disease, edited by E. Braunwald, W.B. Saunders Company, Philadelphia, p. 969 .

10) Fryda, R.J., Kaplan, S. \& Helmworth, J.A. (1971) Postoperative complete heart block in children. Brit. Heart J., 33, 456-462.

11) Haneda, K., Kagawa, Y., Suzuki, Y., Tadokoro, M., Sato, N., Shibota, Y. \& Horiuchi, T. (1975) Postsurgical complete A-V block. J. Jap. Ass. thorac. Surg., 23, 958-963. (Japanese)

12) Horiuchi, T., Koyamada, K., Matano, I., Mohri, H., Komatsu, T., Honda, T., Ishitoya, T., Sagawa, Y., Matsuzawa, K., Matsumura, M., Tsuda, T., Ishizawa, E., Ishikawa, S., Suzuki, H. \& Saito, H. (1963) Radical operation for ventricular septal defect in infancy. J.thorac. cardiovasc. Surg., 46, 180-190.

13) Horiuchi, T., Koyamada, K., Ishitoya, T., Honda, T., Sagawa, Y., Matsumura, M., Tsuda, T., Ishikawa, S., Ishizawa, E. \& Sato, Y. (1964) Analysis of 122 operated case of ventricular septal defects. Jap. J.thorac. Surg., 17, 472-478. (Japanese)

14) Ishizawa, E., Horiuchi, T., Ito, T., Sato, K., Tabayashi, K., Suzuki, Y., Sato, S., Tadokoro, M. \& Kagawa, Y. (1980) Long-term results following surgical repair of certain congenital heart disease. J. Jap. Ass. thorac. Surg., 81, 882-885. (Japanese)

15) Ito, T. (1980a) Serial assessment of carebral function and intellectual development of infants and children following radical open heart surgery using hypothermia. $J$. Jap. Ass. thorac. Surg., 28, 1215-1221. (Japanese)

16) Ito, T. (1980b) An investigation of the intellectual and physical development of children following radical open heart surgery using hypothermia. J. Jap. Ass. thorac. Surg., 28, 1222-1228. (Japanese)

17) Ito, T., Horiuchi, T., Suzuki, Y., Tanaka, S., Ishizawa, E., Tadokoro, M., Satoh, K., Ogasawara, N., Hiraga, H., Kanoh, I., Iimura, K., Satoh, T., Maruyama, N., Ohyama, Y. \& Kamiyama, I. (1976) Serial assessment of carebral function on infants undergoing open-heart sugery under hypothermia. Shinzo, 8, 501-508. (Japanese)

18) Kagawa, Y., Nitta, S., Sato, N., Suzuki, Y., Haneda, K., Saji, K., Shibota, Y. \& Horiuchi, T. (1974) Complication and follow-up study of 75 pacemaker implants in 54 patients. Jap. J. Artif. Organs, 3, 343-349. (Japanese)

19) Kagawa, Y., Horiuchi, T., Ishizawa, E., Ito, T., Suzuki, Y., Arai, S., Sekino, Y., Sato, N. \& Haneda, K. (1986) Late follow-up results of the ventricular septal defect. $J$. Jap. Ass. thorac. Surg., 34, 605-607. (Japanese)

20) Keith, J.D., Rose, V., Collins, G. \& Kidd, B.S.L. (1971) Ventricular septal defect: Incidence, morbidity and mortality in various age groups. Brit. Heart $J$., 33, Suppl. 81-87.

21) Kirklin, J.W. \& Barratt-Boyes, B.G. (1986) Ventricular septal defect. In : Cardiac Suregry, edited by J.W. Kirklin \& B.G. Barratt-Boyes, A Wiley Medical Publication, New York, pp. 559-664.

22) Kirklin, J.W., DuShane, J.W. \& Patrick, R.T. (1955) Intracardiac surgery with the aid of mechanical pump-oxygenator system (Gibbon type). Report of eight cases. Mayo Clin. Proc., 30, 201-206.

23) Kurita, M. (1972) Present status of national nutritive condition. In: Survey of National Nutritive Condition, edited by Nutrition Division, Public Health Bureau, Japanese Ministry of Health and Welfare, Daiichi Shuppan, Tokyo, p. 111.

24) Lillehei, C.W., Cohen, M., Warden, H.E., Ziegler, N.R. \& Varco, R.L. (1955) The results of direct vision closure of ventricular septal defects in eight patients by means of controlled cross circulation. Surg. Gynec. Obstet., 101, 446-466.

25) Lillehei, C.W., Anderson, R.C., Eliot, R.S., Wang, Y. \& Ferlic, R.M. (1968) Pre- and postoperative cardiac catheterization in 200 patients undergoing closure of ventricular septal-defects. Surgery, 63, 69-76.

26) Lincoln, C., Jamieson, S., Joseph, M., Shinebourne, E. \& Anderson, R.H. (1977) Transatrial repair of ventricular septal defects with reference to their anatomic 
classification. J. thorac. cardiovasc. Surg., 74, 183-190.

27) Messmer, B.J., Schallberger, V., Gattiker, R. \& Senning, A. (1976) Psychomotor and intellectual developement after deep hypothermia and circulatory arrest in early infancy. $J$. thorac. cardiovasc. Surg., 72, 495-502.

28) Nora, J.J. \& Nora, A.H. (1978) The evolution of specific genetic and environmental counseling in congenital heart disease. Circulation, 57, 205-213.

29) Rein, J.G., Freed, M.D., Norwood, W.I. \& Castaneda, A.R. (1977) Early and late results of closure of ventricular septal defect in infancy. Ann. thorac. Surg., 24, 1927.

30) Rizzoli, G., Blackstone, E.H., Kirklin, J.W., Pacifico, A.D. \& Bergeron, L.H.J. (1980) Increment risk factor in hospital mortality after repair of ventricular septal defect. $J$. thorac. cardiovasc. Surg., 80, 494-505.

31) Sigmann, J.M., Perry, B.L., Behrendt, D.M., Stern, A.M., KIrsh, M.M. \& Sloan, H.E. (1977) Ventricular septal defect: Results after repair in infancy. Amer. J. Cardiol., 39, 66-71.

32) Steeg, C.N., Kongrad, E., Davachi, F., Bowman, F.O., Jr., Malm, J.R. \& Gersony, W.M. (1975) Postoperative left anterior hemiblock following repair of tetralogy of Fallot: Clinical and etiological considerations. Circulation, 51, 1026-1029.

33) Stevenson, G., Stone, E.F., Dillard, D.H. \& Morgan, B.C. (1974) Intellectual developement of children subjected to prolonged circulatory arrest during hypothermic open-heart surgery in infancy. Circulation, 49-50 Suppl. II, 54-59.

34) Suzuki, Y., Ishizawa, E., Tanaka, S., Itoh, T., Satoh, K., Koizumi, S., Tadokoro, M., Horiuchi, T., Satoh, T. \& Kanoh, I. (1976) Surgical treatment of large ventricular septal defect with pulmonary hypertension in first 24 months of life. Ann. thorac. Surg., 22, 228-234.

35) Takaishi, M., Fujimoto, K. \& Omori, S. (1976) Study on physical developement of infants: Developemental percentile of infants and babies. Shonihoken Kenkyu, 34, 340-345. (Japanese)

36) Takaishi, M., Fujimoto, K. \& Omori, , S. (1977) Study on physical development of children : Developmental percentile of children and school children. Proceeding of 24 th Meeting for Japanese School Health Sosiety (Abstract). (Japanese)

37) Wolff, G.S., Rowland, T.W. \& Ellison, R.C. (1972) Surgically induced right bundle branch block with left anterior hemiblock: An ominous sign in postoperative tetralogy of Fallot. Circulation, 46, 587-594. 